\title{
Pedagogos construindo suas identidades: entre adscrição e escolhas
}

\section{Educationalists building their identities: between submission and choices}

\author{
João Paulo Pooli* \\ Valéria Milena Rohrich Ferreira*
}

\begin{abstract}
RESUMO
$\mathrm{O}$ artigo discute sobre as configurações das identidades dos pedagogos, tendo como referência principal as múltiplas dimensões que são oferecidas e as atividades que esses profissionais assumem no campo de trabalho. As análises realizadas nesse texto partem principalmente das contribuições de Stuart Hall, Zygmunt Bauman e Norbert Elias. Por meio de uma pesquisa realizada com coordenadores pedagógicos de escolas públicas da cidade de Curitiba, podemos compreender que no processo de construção da identidade do pedagogo, coexistem duas disposições: uma escolhida e estruturada na formação acadêmica, e outra urdida no dia a dia através das reais condições estruturais e conjunturais encontradas nas escolas. Concluímos que a concepção acadêmica sobre a identidade do pedagogo foi transformada, mas as estruturas administrativas escolares permaneceram quase intactas. O resultado disso é uma precarização do trabalho do pedagogo, que passa a assumir praticamente todas as demandas que envolvem alunos e professores nas escolas.
\end{abstract}

Palavras-chave: Identidade. Pedagogo. Escola. Norbert Elias. Stuart Hall.

\begin{abstract}
This article discusses the configurations of educationalist identities, having the multiple offered dimensions and the activities which are taken over by these professionals in their working area as a primary point of reference. The analyses made in this text owe a lot to the contributions of Stuart

* Universidade Federal do Paraná. Setor de Educação. Curitiba, Paraná, Brasil. Rua General Carneiro, nº 460. Centro. CEP: 80060-150. E-mails: jpooli@icloud.com; valeriarohrich@gm
\end{abstract}


Hall, Zygmunt Bauman and Norbert Elias. Through a research done with pedagogical coordinators in public schools in Curitiba, we could see that two dispositions co-exist in the process of educationalist identity construction: one of them is chosen and structured during higher education, and the other one is produced in everyday situations through the real structural and conjunctural conditions present at schools. We concluded that the academic conception about educationalist identity was modified, yet the school administrative structures remain almost intact. It results in precarious conditions at the work of educationalists, who have to answer to almost all the demands that involve students and teachers at school.

Keywords: Identity. Educationalist. School. Norbert Elias. Stuart Hall.

[...] eu pensei que iria mudar o mundo, e resolver todos os problemas como pedagoga.

\section{Introdução}

De forma mais ou menos consensual, tem se definido identidade como um processo de tornar idênticas determinadas características individuais ou coletivas, a fim de também as diferenciar. A modernidade foi muito eficaz na produção social e individual da identidade, tentando encaixar o sujeito em processos de pertencimento e ajustamento a uma determinada realidade. Quando falamos em brasileiros, gaúchos, nordestinos, ou mesmo professores, pedagogos, médicos e operários, homogeneizamos um conjunto muito grande de pessoas singulares, por meio de características muito amplas que tornam opacas as particularidades. Marcando o país, o estado, o município, o local de residência ou de trabalho pode-se homogeneizar grupos recorrendo-se a um único significado. Mas, como argumenta Stuart Hall (1997) muita coisa fica "de fora".

Bauman (2005) acreditava que somente pensamos em identidade quando não estamos seguros do lugar ao qual pertencemos, quando não estamos seguros da aceitação do nosso comportamento em relação ao comportamento dos outros, devido principalmente às múltiplas variedades de estilos de vida que a sociedade nos oferece. Muitas vezes, para justificar nossas ações, buscamos auxílio e abrigo na identidade: agi desta maneira porque pertenço a esse ou aquele grupo. De certa maneira, a identidade pode ser uma forma de acolhimento, pertencimento, vinculação ou mesmo de relacionamento. É uma forma 
de ancorar nossas expectativas e angústias dando-lhe um porto seguro, mesmo que o mar da contemporaneidade esteja envolto em constantes tempestades.

A modernidade foi caracterizada como uma época de fixação e de busca do equilíbrio, frente aos desequilíbrios causados por eventos, como as revoluções inglesa, francesa, americana e industrial que sacudiram a antiga ordem feudal. Tudo o que era sólido desmanchava no ar, disse Karl Marx interpretando seu tempo. Assumir uma identidade era uma preocupação iluminista: meio filosófica, meio sociológica, em busca de explicações que dessem conta das emergentes perspectivas de indivíduo e de sociedade. Nesse sentido, a concepção de uma identidade única, para toda a vida, procurava dar sentido às buscas dos sujeitos modernos por si mesmos.

Stuart Hall (2003, p. 14-16) tenta fugir dos problemas que a designação identidade possui, encontrando na identificação uma forma de minimizar os problemas conceituais que esse campo oferece. Para ele, a identificação se constrói no reconhecimento de alguma origem comum, características compartilhadas com outras pessoas, grupos ou ideias. Porém, essa identificação nunca está concluída, é uma construção, um processo em contínua transformação. Ela não apaga as diferenças, porque se constitui como processos de articulação de práticas significantes que necessitam, para se constituir, daquilo que está "fora", ou nas fronteiras. Identidade se transforma assim, em um conceito sem núcleo estável, sem início e fim, que se desenvolve por meio das transformações históricas. Quando fala de identidade cultural, Hall (2003, p. 17) considera que as identidades não se fixam a partir de um eu coletivo que oculta os outros muitos eus. Pelo contrário, ela é altamente fragmentada, fraturada, plural e construída por meio de discursos, práticas e posições entrecruzadas e antagônicas.

Para Hall, as identidades funcionam como pontos de adesão temporária. É um ponto de sutura que tranquiliza o sujeito das suas incertezas e inseguranças, diante das múltiplas interpelações e convites para aderência. Para sustentar uma vida coletiva e individual, as pessoas necessitam de processos de negociação. Essas negociações parecem produzir contínuas demandas por desacomodação, provocando nos sujeitos, ao mesmo tempo, uma necessidade de buscar equilíbrio, devido às constantes interpelações externas desestabilizadoras.

Apesar da fluidez, da transitoriedade, da indeterminação e da imprevisibilidade nas sociedades contemporâneas, mediadas por aparatos eletrônicos de comunicação que tentam constantemente fornecer sentido às nossas vidas humanas, as pessoas continuam se encontrando de corpo e alma, em inúmeros locais públicos e privados. Podemos confortavelmente reconhecer a virtualidade, mas não podemos simplesmente desconhecer que continuamos a frequentar espaços concretos carregados de vida, onde os sujeitos efetivamente estão uns defronte aos outros, em constante relação. 
O sociólogo Norbert Elias (1980) produziu uma teoria bastante original sobre as formações sociais, principalmente dando ênfase às relações que se estabelecem entre a pluralidade de pessoas e a pessoa singular a que chamamos "indivíduo". Há uma tentativa de superar a dicotomia presente até então na sociologia clássica, que separa o indivíduo da sociedade, como se fossem duas entidades dotadas de autonomia, sem vinculação direta e produzindo realidades particulares. A superação dessa separação é muito importante quando se pensa sobre o conceito de identidade.

Está em jogo aqui, o que Elias define como o problema da pessoa singular dentro da pluralidade de pessoas. Ou seja, como me defino e com o que me identifico, dentro de um amplo e complexo conjunto de possibilidades e escolhas que estão disponíveis em configurações sociais diversificadas. Se trata de um ajustamento do homem singular às suas funções e tarefas de adulto (ELIAS, 1993, p. 47), e esse ajustamento de tensões tem relação direta com o que Elias denomina como redes de interdependências, em que a identidade (autoimagem) é o resultado de tensões configuradas numa espécie de tecido entrelaçado que contempla inúmeros fios singulares que estão ligados uns aos outros. Não podemos entender essas configurações a partir de um único fio, ou mesmo de todos os fios singulares em si, mas apenas e exclusivamente a partir da sua interligação, das relações que eles mantêm. Elias entende que a maneira como o indivíduo se vê e se regula nos seus relacionamentos com outros (identidade) depende da estrutura do coletivo humano, ou dos coletivos com os quais aprende a dizer "nós". (1993, p. 58).

$\mathrm{Na}$ atualidade, o desenvolvimento de novas ferramentas de comunicação instantânea e global de uso generalizado, faz a questão de a identidade assumir uma centralidade. A relação entre o que o sujeito pensa sobre si e como ele deseja ser visto pelos outros passa a ter forte carga afetiva e emocional, pois estabelece uma vinculação entre os processos de produção da autonomia que caracteriza o sujeito individual e as suas vinculações com os outros.

Em novas condições de comunicação instantânea (principalmente através de ferramentas como o Facebook, Instagram e o WhatsApp) parece ocorrer um conjunto de práticas de subjetivação que remetem a uma dissociação entre o que o sujeito pensa de si e como ele quer ser visto, independente da realidade. Essa subjetivação não é somente a nossa relação com nós mesmos - um governo de si - mas uma relação que inclui como eu desejo ser visto pelos outros. Há uma forte tentativa de forjamento de personagens públicos idealizados e prontos para o consumo.

Ao contrário do que indicava Richard Sennet (1998), quando apontava para uma tirania da intimidade, hoje há sinais explícitos de um retorno aos sujeitos públicos ansiosos por apresentarem-se em diferentes espaços, lugares e posições, 
com forte conteúdo político, estético e moral. Esses sujeitos são o resultado de uma série de práticas que tentam regular a vida cotidiana. Isso ocorre porque

[...] nuestra relación con nosotros mismos adoptó la forma que tiene porque fue objeto de toda una serie de esquemas más o menos racionalizados que procuraron modelar nuestro modos de entender y llevar a la práctica nuestra existencia como seres humanos en nombre de ciertos objetivos: virilidade, femineidad, honor, modestia, propiedad, civilidade, disciplina, distinción, eficiencia, armonía, realización, virtude, placer, la lista es tan diversa y heterogénea como interminable. (ROSE, 2003, p. 217-218).

A identidade passa a ter uma centralidade nas configurações dos sujeitos, não em um sentido único e definitivo, mas sempre se constituindo, modificando, distinguindo e identificando. A produção da identidade, no caso dos pedagogos, também está vinculada a certos objetivos que dizem respeito às práticas efetivas na profissão.

Assumir uma ou mais atividades, ou profissões, configura-se como uma das diversas dimensões para a constituição da identidade. Ter uma ocupação, em uma sociedade que reverencia o trabalho como qualidade intrínseca dos homens e mulheres, é um elemento de identificação, pertencimento, acolhimento, assim como de segregação, discriminação, estereotipagem e inutilidade individual e social. Fazer algo de útil para si e para a sociedade faz parte de um processo de construção objetiva da vida, tanto nos aspectos relacionados com a satisfação das necessidades básicas, como alimentação, moradia, saúde, educação, cultura e bem-estar, quanto na produção de expectativas de futuro.

As profissões são ocupações que os sujeitos assumem e se expressam em práticas concretas. Se as profissões são reconhecidas pelas práticas, está implícito que elas importam em um conjunto de conhecimentos e capacidades. Assim

Profissões, despojadas de suas roupagens próprias, são funções sociais especializadas que as pessoas desempenham em resposta a necessidades especializadas de outras; são, ao menos em sua forma mais desenvolvida, conjuntos especializados de relações humanas. $\mathrm{O}$ estudo da gênese de uma profissão, portanto, não é simplesmente a apreciação de um certo número de indivíduos que tenham sido os primeiros a desempenhar certas funções para outros e a desenvolver certas relações, mas sim a análise de tais funções e relações. (ELIAS, 2006, p. 89). 
Norbert Elias (2006) argumenta que o surgimento de novas profissões está atrelado ao desenvolvimento das descobertas científicas, das novas necessidades humanas e dos meios de satisfazê-las. É na interação desses fatores (técnicas, instituições e necessidades humanas), em consonância com as tensões e as discrepâncias entre grupos de pessoas que se constitui o motor do desenvolvimento de uma profissão.

Disparidades podem surgir ora em virtude de mudanças técnicas, ora em consequência de condições e exigências sociais. Quaisquer que sejam suas causas imediatas, elas criam dificuldades específicas, produzem atritos e conflitos, confrontam cada membro de uma profissão com problemas que não são por ele criados. No entanto, uma vez que ele esteja em uma profissão, esses problemas institucionais se tornam seus próprios problemas, essas dificuldades, suas próprias dificuldades, esses conflitos, seus próprios conflitos. E as soluções não estão inteiramente em suas mãos. (ELIAS, 2006, p. 90).

Esses argumentos abrem caminho para que possamos analisar uma profissão como parte de um conjunto de relações que se configuram ao longo do tempo e são mediadas pelas condições concretas do seu exercício e das instituições onde são praticadas.

As relações entre teoria e prática formam o núcleo estrutural das Ciências da Educação. No entanto, e não menos importante, caminha pari passu às questões que envolvem o campo da gestão escolar, no sentido de encontrar meios para compatibilizar as teorias e as práticas com a organização financeira, a administrativa, a política, a didática-metodológica e com a comunidade escolar. Para todas essas articulações, as legislações, por meio dos seus formuladores, que em geral são educadores, designaram aos pedagogos um conjunto muito amplo de tarefas.

No Brasil, os profissionais que cursam Licenciatura em Pedagogia estão habilitados para exercer a docência e a gestão, com um conjunto de funções específicas. O Conselho Nacional de Educação (CNE), através da instituição das Diretrizes Curriculares Nacionais para o Curso de Graduação em Pedagogia (Parecer CNE/CP N ${ }^{\circ}$ 05/2005) - DCNP, trata das "aptidões" que devem ter os egressos. Ao mesmo tempo que essa legislação institui, ela delimita, designando quais as atividades que devem ocupar os pedagogos nas escolas. Nesse sentido, pode-se ler no documento que: 
Enfatiza-se ainda que grande parte dos cursos de Pedagogia, hoje, tem como objetivo central a formação de profissionais capazes de exercer a docência na Educação Infantil, nos anos iniciais do Ensino Fundamental, nas disciplinas pedagógicas para a formação de professores, assim como para a participação no planejamento, gestão e avaliação de estabelecimentos de ensino, de sistemas educativos escolares, bem como organização e desenvolvimento de programas não-escolares. Os movimentos sociais também têm insistido em demonstrar a existência de uma demanda ainda pouco atendida, no sentido de que os estudantes de Pedagogia sejam também formados para garantir a educação, com vistas à inclusão plena, dos segmentos historicamente excluídos dos direitos sociais, culturais, econômicos, políticos. (BRASIL, 2005, p. 5).

As DCNP mesclam as atribuições, tipicamente docentes, em consonância com as que podem ser classificadas como atividades de gestão pedagógica nas escolas. Inclui, além disso, uma formação política que parece assumir um caráter mágico-mítico", em que o pedagogo deveria "garantir inclusão plena dos excluídos" (não explicitando como isso seria realizado). Essas "aptidões" podem auxiliar a definir uma identidade do pedagogo, inserido nas circunstâncias políticas, econômicas e culturais contemporâneas, caso se entenda a identidade como um processo de identificação entre o que o sujeito faz e como ele se reconhece naquilo que está realizando.

$\mathrm{O}$ que interessa para esse artigo são as atribuições que os egressos deveriam ter para exercer suas funções. Estas fazem parte das DCNP que, no seu artigo $5^{\circ}$, indica que os egressos do curso de Pedagogia deverão estar "aptos a":

I - atuar com ética e compromisso com vistas à construção de uma sociedade justa, equânime, igualitária;

II - compreender, cuidar e educar crianças de zero a cinco anos, de forma a contribuir, para o seu desenvolvimento nas dimensões, entre outras, física, psicológica, intelectual, social;

1 Essa expressão reporta a Norbert Elias quando afirma que "hoje gostamos de pensar que o elemento de fantasia, que desempenha um papel importante na orientação das acções e ideias de um grupo relativamente às suas metas, não é mais do que um esconderijo - um disfarce sedutor e excitante de propaganda. [...] Até agora, a história não tem sido mais do que um cemitério de sonhos humanos. Os sonhos realizam-se muitas vezes a curto prazo; contudo, no seu longo curso, parecem sempre acabar esvaziados de toda a substância, sendo, portanto, destruídos. A causa é que esperanças e objectivos a alcançar estão de tal forma saturados de fantasia, que o atual curso de conhecimentos na sociedade lhes desfere golpes consecutivos e o choque com a realidade revela sua irrealidade, como sonhos que são.” (ELIAS, 1980, p. 29-30). 
III - fortalecer o desenvolvimento e as aprendizagens de crianças do Ensino Fundamental, assim como daqueles que não tiveram oportunidade de escolarização na idade própria;

IV - trabalhar, em espaços escolares e não escolares, na promoção da aprendizagem de sujeitos em diferentes fases do desenvolvimento humano, em diversos níveis e modalidades do processo educativo;

$\mathrm{V}$ - reconhecer e respeitar as manifestações e necessidades físicas, cognitivas, emocionais, afetivas dos educandos nas suas relações individuais e coletivas;

VI - ensinar Língua Portuguesa, Matemática, Ciências, História, Geografia, Artes, Educação Física, de forma interdisciplinar e adequada às diferentes fases do desenvolvimento humano;

VII - relacionar as linguagens dos meios de comunicação à educação, nos processos didático-pedagógicos, demonstrando domínio das tecnologias de informação e comunicação adequadas ao desenvolvimento de aprendizagens significativas;

VIII - promover e facilitar relações de cooperação entre a instituição educativa, a família e a comunidade;

IX - identificar problemas socioculturais e educacionais com postura investigativa, integrativa e propositiva em face de realidades complexas, com vistas a contribuir para superação de exclusões sociais, étnico-raciais, econômicas, culturais, religiosas, políticas e outras;

$\mathrm{X}$ - demonstrar consciência da diversidade, respeitando as diferenças de natureza ambiental-ecológica, étnico-racial, de gêneros, faixas geracionais, classes sociais, religiões, necessidades especiais, escolhas sexuais, entre outras;

XI - desenvolver trabalho em equipe, estabelecendo diálogo entre a área educacional e as demais áreas do conhecimento;

XII - participar da gestão das instituições contribuindo para elaboração, implementação, coordenação, acompanhamento e avaliação do projeto pedagógico;

XIII - participar da gestão das instituições planejando, executando, acompanhando e avaliando projetos e programas educacionais, em ambientes escolares e não-escolares;

XIV - realizar pesquisas que proporcionem conhecimentos, entre outros: sobre alunos e alunas e a realidade sociocultural em que estes desenvolvem suas experiências não-escolares; sobre processos de ensinar e de aprender, em diferentes meios ambiental- ecológicos; sobre propostas curriculares; e sobre organização do trabalho educativo e práticas pedagógicas; $\mathrm{XV}$ - utilizar, com propriedade, instrumentos próprios para construção de conhecimentos pedagógicos e científicos;

XVI - estudar, aplicar criticamente as diretrizes curriculares e outras determinações legais que lhe caiba implantar, executar, avaliar e encaminhar o resultado de sua avaliação às instâncias competentes. (BRASIL, 2005, p. 20-21). 
Como se pode observar, as DCNP são maximalistas em determinadas demandas, como a construção de uma sociedade justa, equânime e igualitária; o ensino de forma interdisciplinar e adequada; o domínio das tecnologias de informação e comunicação; o desenvolvimento de aprendizagens significativas; a postura investigativa, integrativa e propositiva em face a realidades complexas; a contribuição para a superação de exclusões sociais, étnico-raciais, econômicas, culturais, religiosas, políticas e outras; a demonstração da consciência da diversidade; o respeito as diferenças de natureza ambiental-ecológica; o uso com propriedade de instrumentos próprios para a construção de conhecimentos; a aplicação crítica das diretrizes curriculares. Essas aptidões são quase impossíveis de ser implementadas na atual realidade das escolas, assim como são temáticas e conceitos controversos que exigem um longo debate filosófico-sociológico e pedagógico, de difícil consenso, mesmo entre os intelectuais que buscam afirmar esses discursos e práticas.

Por outro lado, as DCNP são também minimalistas quando não consideram as práticas cotidianas efetivas dos pedagogos e suas reais necessidades nas escolas. Entre elas podemos citar as mais recorrentes, como o preenchimento de fichas de frequência e infrequência; a entrega de boletins e comunicado aos pais; as questões de relacionamento entre alunos e alunos e professores; $\mathrm{o}$ assessoramento à direção; o conflito entre professores; o controle de frequência e a substituição de professores; as aulas de reforço escolar; a resolução de conflitos referentes a racismo, sexualidade, gênero, drogadição e violência; a organização e controle de atividades culturais, esportivas e de passeios e visitas fora da escola. Além dessas atividades, muitas vezes se veem obrigados a cuidar da disciplina, dos uniformes e da entrada e saída dos alunos. Como se verá mais à frente, essas são apenas algumas tarefas que acabam sendo assumidas pelos pedagogos, em geral, motivados pela insuficiência de pessoal para assumir essas obrigações.

A solução para esse problema, certamente não passa por acrescentar nas DCNP as ocupações que não estão especificadas. O que se faz necessário é delimitar qual é especificamente o trabalho do pedagogo nas escolas, tendo como base as contribuições das Ciências da Educação para os processos educativos escolares.

Tradicionalmente os cursos de formação pensam o pedagogo pela sua participação na direção, no planejamento, organização, execução e avaliação das políticas educativas, no assessoramento aos processos didático-metodológicos, na sistematização do currículo escolar e na coordenação das relações com a comunidade escolar. A formação e a atuação do pedagogo nos ambientes educativos é que configuram a sua identidade que, como já afirmado anteriormente, não é fixa nem imutável. Ela faz parte do desenvolvimento histórico, social e político da sociedade que é intrinsecamente contraditório e transitório, provocando 
uma contínua reconceitualização de significados. É no exercício da profissão que os pedagogos vão ajustando a sua identidade, tendo como parâmetros as formulações da legislação, as certezas da sua formação e as incertezas que a realidade vai lhes impondo.

\section{A precarização do trabalho produzindo identidades}

Na disciplina de Estágio e de Organização do Trabalho Pedagógico, do curso de graduação em Pedagogia da UFPR, os professores do turno da manhã, juntamente com as alunas e alunos que estão em estágio no $5^{\circ}$ ano, após análises sobre literatura que trata do tema da identidade do pedagogo, entrevistaram as pedagogas e os pedagogos das escolas em que faziam o estágio. Entre os anos de 2014 e 2015, foram realizadas entrevistas semi-estruturadas com estes profissionais, depois foram transcritas e incluídas em seus relatórios de estágio ${ }^{2}$. Foi com base nessas transcrições que apontamos alguns elementos para pensar as identidades dos pedagogos que trabalham em algumas escolas públicas de Curitiba.

Sobre as funções dos pedagogos, os entrevistados/as afirmaram acreditar que esta é primordial para que uma escola funcione. No entanto caracterizam o seu trabalho como de articulação/mediação entre instâncias que participam das atividades da escola. Destacam que o pedagogo:

[Deve] saber ouvir, lidar e mediar conflitos com alunos e entre os professores. Deixar o professor falar sempre. Valorizar cada ação intencional e direcionada, orientar quem precisa. (Entrevistada N, 42 anos, escola municipal).

O pedagogo é o profissional que articula compreensões e reflexões sobre as práticas de forma mais apurada e global. (Entrevistada H, 38 anos, colégio estadual).

2 Trabalhamos até este momento, com 15 entrevistas realizadas com pedagogas e pedagogos de escolas estaduais e municipais. A metade destes profissionais continuavam em um período como professores e no outro como pedagogos, ou, nos casos em que atualmente só eram pedagogos, tinham atuado muitos anos como professores, antes de serem pedagogos. 
Ele é acolhedor, pacificador, orientador, ele é o articulador, é o coração palpitante da escola. Sem o pedagogo a escola não caminha. Nós temos todas as outras funções, mas a função do pedagogo é a primordial para que uma escola caminhe dentro dos trilhos, é o principal articulador para que uma escola dê certo, para uma escola de qualidade. (Entrevistada G, 47 anos, colégio municipal).

Assim, configuram sua profissão como tendo um caráter articulador, mediador, facilitador. Ele é a ponte entre várias instâncias, como a Secretaria Municipal ou Estadual de Educação e com os Núcleos Regionais. É considerado também como o mediador entre os segmentos e como um sujeito que "costura" as relações na escola entre professores, direção, secretaria, inspetoras, alunos e a comunidade.

Para os pedagogos, é necessário um envolvimento com todas as questões da escola: "Deve trabalhar com os alunos e professores mediando situações de aprendizagem e conflitos"; "atuar na gestão escolar, organizando o processo de ensinar e aprender na relação entre professor, aluno e conhecimento"; "ter relação com a comunidade, com o núcleo, pais e responsáveis" e ainda "trabalhar com todas as turmas, com pais, alunos, professores, direção, administrativo, com tudo!".

Dentre tantas mediações, ocupar-se do desenvolvimento curricular é o menos citado, porém mais ambicionado: "A pedagoga deveria atuar sistematicamente em sala de aula e na construção do planejamento". (Entrevistada N, 42 anos, escola municipal). A pouca aproximação com o campo curricular parece se dar pelas inúmeras outras articulações que são feitas no cotidiano: "tem que ter jogo de cintura, tem que saber lidar com pai, você tem que saber conversar com o professor, aluno, você tem que estar ali pra lá e pra cá..." (Entrevistada $\mathrm{N}, 42$ anos, escola municipal).

Nesse sentido, o pedagogo seria um "faz tudo", um "Bombril: mil e uma utilidades", um verdadeiro "bombeiro". Sua identidade é sempre atravessada pela angústia e pela tensão entre aquilo que ele acha que deveria fazer como pedagogo (a sua formação) e aquilo que realmente faz. Muitas vezes, alguns pedagogos tentam evitar algumas tarefas que não estão vinculadas às suas funções para poderem fazer um pouco daquilo que consideram importante:

[O desejo é o de] não só apagar incêndio, mas, desenvolver um trabalho consistente pra trabalhar com o professor, o encaminhamento metodológico, desenvolver projetos na escola. Muitas atribuições 
deixamos de fazer em função do que acontece no dia a dia da escola. (Entrevistada K1, 60 anos, colégio estadual).

Hoje a gente apaga muito incêndio e muitas vezes nós não conseguimos fazer o que realmente é a função do pedagogo, que é trabalhar com o aluno a parte pedagógica e com o professor. Muitas vezes você passa o dia apagando incêndio e a parte pedagógica é deixada de lado, então o meu sonho é que um dia exista uma pessoa que trabalhe só com essa parte disciplinar, para que a gente só trabalhe com a parte pedagógica realmente. (Entrevistada J, 45 anos, colégio estadual).

Outro fator é o fato da pedagoga sempre ter de estar disponível a todos e a tudo, o tempo todo. Múltiplas solicitações, por ordem da comunidade escolar e ainda dos órgãos a que estão submetidos, não podendo fazer o trabalho que é realmente pedagógico. (Entrevistada A, 45 anos, escola municipal).

Os seus relatos demonstram que a realidade imediata não permite que eles simplesmente não atendam as demandas cotidianas. Assumir tarefas como organização e disciplina são importantes para a manutenção de uma determinada ordem no funcionamento das escolas. Essas atividades são derivadas de acordos dispostos no Projeto Político Pedagógico, no Regimento Escolar, decisões da Comunidade Escolar, ou mesmo de determinações dos órgãos gestores.

É importante destacar que, na atual estrutura administrativa das escolas, não há designação de pessoal para cuidar dessas obrigações, embora tenha um funcionário - normalmente o inspetor escolar - controlando o fluxo de alunos nos corredores ou no pátio, quando estão fora de sala de aula.

A função generalista/unitária assumida pelos pedagogos atualmente deriva de uma nova concepção sobre a identidade desse profissional. Brzezinski (2011) abordou esse problema com precisão, e não é nosso objetivo discutir acertos e equívocos das mudanças de concepção, mas sim refletir sobre os desdobramentos dessa nova concepção para o trabalho dos pedagogos nas escolas.

A mudança da concepção do trabalho pedagógico, de uma perspectiva tecnicista para unitária, inspirada por uma visão gramsciana, principalmente no Paraná, é ainda hoje defendida com grande ênfase. Para uma das entrevistadas, o pedagogo 
[...] é aquele que então não divide né, ... é aquele que não é nem o Bombril, mil e uma utilidades, porque isso não é unitário isso vai ser um por turno e unitário porque ele é sozinho, um por turno, não é isso. Mas não há pedagogo que dualiza, porque o pedagogo que dualiza a orientação e a supervisão é o taylorista. Numa lógica taylorista a gente tem essa dualidade entre o supervisor, que é aquele que então vai reproduzir o modo de produção capitalista a partir do controle, e o orientador que vai fazer o papel do assistente social compensando as desigualdades do capitalismo do cotidiano do aluno. Então, romper com essa visão de pedagogo dualista e chegar numa concepção unitária de pedagogo foi muito com a ajuda do olhar da Acácia Kuenzer, que eu acho que me ajudou sim na prática de romper. Não é nem superar porque acho que no mundo do capitalismo não supera nada, né? (Entrevistada I, 44 anos, colégio estadual).

Sem entrar na discussão sobre viabilidade ou validade da concepção de pedagogo unitário, duas questões são inevitáveis. A primeira se refere à concepção filosófica-gramsciana que pressupõe um profissional ontologicamente omnilateral que tenha como projeto político a fundação de uma nova sociedade, mais justa e igualitária. Essa concepção pressupõe uma nova identidade do pedagogo, forjada mediante uma relação indissociável entre concepção e prática. O problema que se apresenta são as múltiplas e contraditórias circunstâncias da realidade, onde o efetivo exercício da profissão não ocorre em condições ideais. E também a concepção de trabalho pedagógico proferido pelas DCNCP foi pensada a partir do pressuposto idealizado de que as escolas teriam todas as condições para o exercício da profissão. Mas não é isso o que ocorre na realidade da maioria das escolas.

O pedagogo unitário tem que enfrentar a dura realidade do sucateamento da escola pública e a precarização do trabalho pelo oportunismo de muitos gestores que se utilizam da concepção de pedagogo unitário como justificativa ardilosa para corte de pessoal, já que ele foi formado para ser gestor, orientador educacional e supervisor escolar.

Assim, no processo de construção da identidade do pedagogo, coexistem duas disposições: uma escolhida e estruturada na formação acadêmica e outra urdida no dia a dia nas reais condições estruturais e conjunturais encontradas nas escolas. Ao mesmo tempo que os pedagogos se preparam para desempenhar funções idealizadas, eles são rotineiramente confrontados pelas "sobras de identidades antigas" (BAUMAN, 2005, p. 45). Isto é, convivem de maneira simultânea tanto o pedagogo unitário como o pedagogo com a clássica fragmentação entre orientação, supervisão e administração. Em algumas escolas de 
grande porte, com um maior número de pedagogos, não é raro que eles dividam as tarefas cotidianas, cada um se ocupando de uma área, como se estivessem ainda sob a lógica das habilitações.

Essa questão remete à relação entre as inovações produzidas pelas teorias acadêmicas e a concreta realidade de funcionamento das escolas públicas. Não se trata de criticar as produções teóricas da academia, muito pelo contrário, elas são necessárias e imprescindíveis para o desenvolvimento da sociedade. $\mathrm{O}$ problema é quando há uma desobrigação de estabelecer um nexo causal entre pensamento e realidade.

Outra questão é que a concepção acadêmica sobre a identidade do pedagogo foi transformada, mas as estruturas administrativas escolares permaneceram quase intactas. O resultado disso é uma precarização do trabalho do pedagogo, que passa a assumir praticamente todas as demandas que envolvem alunos e professores nas escolas. Como dissemos anteriormente, essa situação se torna muito favorável aos gestores do sistema que deixam de se preocupar com a multiplicidade de funções necessárias ao cotidiano da escola, defendendo a ideia de que um só servidor poderá assumir todas essas funções.

A principal insatisfação dos pedagogos em relação às suas atividades diárias se refere ao escasso e insuficiente trabalho pedagógico que conseguem desenvolver com os professores e alunos. Entre as funções precípuas em sua formação está a intervenção nos processos de ensino e aprendizagem, com o objetivo de qualificar todas as experiências educativas da comunidade escolar. O Projeto Político Pedagógico do Curso de Pedagogia da UFPR, por exemplo, é bastante enfático quanto a essa formação:

Esta concepção de pedagogo impõe duas questões fundamentais. A primeira refere-se à centralidade do binômio ensino/aprendizagem como âmago do trabalho pedagógico, seja na organização do trabalho pedagógico em toda a educação básica, seja como professor de educação infantil, séries iniciais do ensino fundamental e disciplinas do magistério ou ainda, na produção e divulgação de conhecimentos voltados à superação dos graves problemas da área educacional no contexto da escola brasileira atual. (UFPR, 2007, p. 36).

A identidade do pedagogo se sustenta em grande parte na expectativa de que essa função seja efetivamente exercida nas escolas. A frustração em realizar a profissão que escolheram causa um sentimento de desvalorização e de não reconhecimento social devido à precariedade dos resultados, como fica claro abaixo: 
Eu para ser pedagogo ainda falta muito. O que é ser pedagogo? O pedagogo cuida do pedagógico, heeer! (risos) o mais óbvio. E eu faço o pedagógico? Não, eu fico preso com problemas que atrapalham o pedagógico. Digamos assim: eu não defendo o pedagógico só, né? Eu atendo criança com dor de barriga, eu trabalho com o negócio do FICA, com ADP, faço encaminhamentos médicos também, mas eu faço o pedagógico? Não, eu faria se eu tivesse acompanhando a didática do professor em sala de aula também. (Entrevistada L, 34 anos, colégio municipal).

Porque você veja, quantas pessoas que estamos falando aqui... já vieram pra falar comigo, por problemas que qualquer um pode resolver, a inspetora pode resolver. Por que o que elas querem? Querem a chave de pegar o livro da sala dos livros, isso a inspetora podia ficar com a chave, eles querem... cheguei agora é problema meu? É o problema da inspetora, o que é que ela vai fazer... é o fulano não quis virar o boné para trás, então o professor tira ele da sala de aula, quem é que tem que interferir? Quem é que faz esse meio campo com o professor e o aluno? (Entrevistada M, 56 anos, colégio estadual).

[O que deveria ser:] acompanhamento do professor para sala de aula, facilitar o trabalho do professor em sala de aula. O que eu faço é outra coisa... não que a gente deixa de fazer isso, nos acabamos... o pedagogo é visto como: você só sabe cobrar, que sabe pedir, você só sabe..., entendeu? Ele não vê como facilitador pra ele e sim um agente de cobrança, porque nós não conseguimos parar com o professor para estudar.. o que tá dando certo... (Entrevistada M, 56 anos, colégio estadual).

Cada profissional tem que ter sua função, se misturar essas funções vira uma bagunça, então eu realmente perco a minha identidade, perco porque no momento eu estou sozinho e o pedagogo é aquela antiga velha história que todo mundo fala: o pedagogo tem que ser médico, precisa ser psicólogo, precisa exercer um monte de tarefa que acaba não fazendo o pedagógico. (Entrevistada L, 34 anos, colégio municipal).

A gente faz além do que é a nossa função, a escola tem esta necessidade, principalmente porque o poder público não consegue atender a demanda. (Entrevistada C, 52 anos, colégio estadual). 
Em relação à participação do trabalho na construção da identidade, pode-se inferir que os pedagogos têm uma interdição da identidade pensada. Bauman (2005, p. 44-45), tratando dos processos de identificação, cita dois polos: os que mais ou menos, através de vontade própria, escolhem sua identidade num leque de ofertas amplas e os que têm essas escolhas negadas, que não podem manifestar suas preferências, que se veem oprimidos por identidades impostas, as quais não têm permissão para abandonar e nem das quais conseguem se livrar. E os que lutam pela identidade que acreditam ficam muito desconfortáveis com sua situação:

[...] porque, se a gente não tiver claro isso a gente perde a autonomia, $e$ ai o pedagogo vira o fazedor, o cumpridor de tarefas, perde a autonomia de pensar, e perde e perde. Quando chega na escola vira aquela coisa, o Núcleo mandou, a secretaria mandou, não sei quem mandou. Tá, e a autonomia do pensamento? Se eu domino a lei, se eu entendo quais são os princípios básicos da Constituição, se eu entendo que é a minha função precipua de edital, porque eu tenho que ser subserviente com o que os outros mandam? (Entrevistada I, 44 anos, colégio estadual).

A função é desgastante e frustrante pois tornou-se muito mais burocrática do que efetivamente pedagógica, consumindo muito tempo e não dando resultado igual ao da sala de aula. As demandas burocráticas atrapalham o desenvolvimento de um trabalho pedagógico consistente e isso se torna um dos desafios no seu trabalho. Assim, a pedagoga procura delegar as ações possiveis para outras pessoas da escola fazendo com que haja mais tempo para as ações propriamente pedagógicas... (Entrevistada M, 56 anos, colégio estadual).

[...] então enquanto eu fiquei fazendo este FICA, fazendo o contato, fazendo este trabalho que não é pedagógico, é burocrático, as minhas professoras ficaram sem atendimento, meus alunos ficaram sem atendimento adequado, porque eu estava envolvido com este outro trabalho. A pergunta é: perdeu a identidade? Absolutamente sim, porque eu poderia ter aqui um estagiário fazendo o FICA e eu vou cuidar do pedagógico. Mas, mesmo assim irão aparecer outras demandas de crianças que precisam de outros atendimentos pedagógicos e eu fico atrás desses atendimentos. E aquelas que não são encaminhadas para atendimento? Só que elas estão ali e ninguém olha para elas, e aí? Acaba que elas perdem nessa questão pedagógica e eu perco minha identidade porque não consigo intervir com elas. (Entrevistada L, 34 anos, colégio municipal). 
Como não conseguem atender as demandas cotidianas, esses pedagogos são subsumidos às circunstâncias objetivas do dia a dia, onde sua margem de escolhas é muito pequena. A adscrição, a sujeição é quase inevitável nesse cenário.

\section{Ambivalência e identidade: que pedagogo, que pedagogia}

Nos processos de construção de identidades, os pedagogos parecem estar em permanente estado de inquietude, provocada pela ambivalência no exercício da sua profissão. Por um lado, a formação acadêmica é toda lastreada por uma concepção identitária voltada para a qualidade dos processos de ensino e aprendizagem, mas, por outro lado, nas suas práticas efetivas e cotidianas, o pedagogo está liquefeito pelas demandas que explodem no dia a dia das escolas. Trata-se de como ser pedagogo sem se sentir deslocado, fora de lugar. Não estar em um lugar é uma experiência desconfortável, e até perturbadora, porque há sempre alguma coisa para explicar, desculpar, esconder, negociar, perder, ostentar e oferecer (BAUMAN, 2005, p. 19). Essa fragilidade potencializa a angústia daqueles que depositaram todas suas esperanças no reconhecimento social da profissão.

Norbert Elias (2006, p. 179) afirma com propriedade que quando os especialistas não conseguem demonstrar que a matéria sobre a qual versam seus trabalhos tem uma lógica própria e que seu estudo requer determinadas habilidades (por meio de uma área do conhecimento específica), sua razão de ser fica ameaçada. A pedagogia parece estar sofrendo uma ameaça desse tipo. Dentro das circunstâncias apontadas nas entrevistas, para o exercício da profissão, fica muito difícil compreender o papel dos pedagogos e a sua contribuição para a educação escolar. Que conexões são possíveis fazer entre o trabalho pedagógico e a qualidade da educação? Como é possível diferenciar o que é especificamente uma intervenção pedagógica daquilo que é função de outros profissionais?

Não podemos esquecer que a identidade se constrói dentro do discurso e não fora dele. É no jogo das relações sociais que a diferença e as exclusões marcam mais do que a homogeneidade artificialmente construída. Muitas vezes a consequência nesse processo é que os pedagogos que conseguem construir uma identidade, por meio de práticas coerentes com sua formação, lutam para se diferenciar daqueles que não conseguem.

Confrontando as propostas teóricas e os imperativos legais de mudanças na identidade do pedagogo com a realidade cotidiana das escolas, é quase impossível não lembrar de Viñao Frago (1996) que, ao estudar a cultura escolar, 
confronta três lógicas de ação: teoria, legalidade e práticas. Para o autor, se por um lado essas três lógicas não coincidem, não são a mesma coisa, por outro, se complementam. E para a discussão que aqui propomos, é importante desnaturalizar cada uma dessas lógicas, colocá-las em contraste para apreender as tensões pelas quais o pedagogo vive, hoje, nas escolas públicas.

Sobre os aspectos teóricos, a formação acadêmica parece lastreada por uma concepção identitária que solidifica uma posição central e indispensável para a qualidade dos processos de ensino e aprendizagem. Mas, ao menos no caso do Paraná, a defesa de um pedagogo unitário, em contraposição ao modelo tecnicista de fragmentação do trabalho escolar, parece ter sido transfigurada e utilizada como uma política exótica de "enxugamento da máquina". Isso ocorre quando acumula diferentes e sobrecarregadas funções em um mesmo sujeito, tendo como consequência direta a diminuição do número de pedagogos nas escolas. A identidade passa, na prática, de um pedagogo unitário para um pedagogo que tudo faz.

Do ponto de vista da legalidade, as DCNCP indicam que os pedagogos devem exercer uma quantidade tão grande de funções que uma das mais centrais, como o desenvolvimento curricular, fica dissolvida entre tantos encargos.

Pelas diretrizes, a multifuncionalidade e a polivalência devem constituir a sua identidade, porém, do ponto de vista das práticas, essa multifuncionalidade e polivalência têm significado dar conta de praticamente tudo o que ocorre na escola.

Sobre essas lógicas de ação, Viñao Frago (1996) ainda acrescenta: “a confrontação entre a teoria, a legalidade e as práticas exige, por sua vez, considerar um quarto aspecto que condiciona, e é condicionado por elas: a realidade escolar externa à escola". O autor aponta que é justamente ao olhar a realidade externa que se pode perceber os limites e as possibilidades do que é proposto ou legislado.

Nesse sentido, grande parte dos estudos sobre o papel e as funções dos pedagogos nas escolas acaba por não problematizar a relação entre a profissão de pedagogo e as demandas de uma sociedade capitalista, informacional.

Muitas vezes as pesquisas e análises sobre o trabalho pedagógico partem de uma concepção a priori da pedagogia como uma ciência que produz soluções definitivas para os problemas da educação. Isso é pura abstração. Na maioria das vezes a escola viva não funciona como a teoria quer. Poucas vezes as pesquisas levam em consideração como os pedagogos lidam com seus problemas cotidianos, como aprendem com sua experiência, como reformulam ou transgridem regras, como improvisam independente das disposições legais e políticas, como resolvem conflitos ou como elaboram novos discursos pedagógicos junto com a 
comunidade escolar. Demasiadas vezes a macropolítica academicista esconde a micropolítica cotidiana. É tempo de aprender com os pedagogos.

\section{REFERÊNCIAS}

BAUMAN, Z. Identidade. Rio de Janeiro: Jorge Zahar Editor, 2005.

BRASIL. Ministério da Educação. Parecer $C N E / C P N^{\circ}$ 05/2005, de 13 de dezembro de 2005. Conselho Nacional de Educação - Conselho Pleno, Brasília, 2005.

BRZEZINSKI, I. Pedagogo: delineando identidade(s). Revista UFG, n. 10, p. 120-132, 2011.

ELIAS, N. Introdução à Sociologia. Braga: Edições 70, 1980.

ELIAS, N. Escritos \& Ensaios: 1. estado, processo, opinião pública. Rio de Janeiro: Jorge Zahar Editor, 2006.

ELIAS, N. A Sociedade dos Indivíduos. Lisboa: Dom Quixote, 1993.

HALL, S. A centralidade da Cultura: notas sobre as revoluções culturais do nosso tempo. Educação \& Realidade, v. 22, n. 2, jul./dez., 1997.

HALL, S. (Org.). Questiones de identidade cultural. Buenos Aires: Amorrortu, 2003.

ROSE, N. Identidad, genealogía, historia. In: HALL, Stuart (Org.). Questiones de identidade cultural. Buenos Aires: Amorrortu, 2003.

SENNETT, R. O declinio do homem público: as tiranias da intimidade. São Paulo: Companhia das Letras, 1998.

UNIVERSIDADE FEDERAL DO PARANÁ (UFPR). Proposta de reformulação curricular para o curso de pedagogia. Curitiba, 2007. Disponível em: $<\mathrm{http} / / /$ www.pedagogia. ufpr.br/ppp.html>. Acesso em: 10 fev. 2017.

VIÑAO FRAGO, A. Por una historia de la cultura escolar: enfoques, cuestiones, fuentes. In: Culturas y Civilizaciones: III CONGRESO DE LA ASOCIACIÓN DE HISTORIA CONTEMPORÁNEA, 3., 1996, Anais... Valladolid: Secretariado de Publicaciones e Intercambio Científico, Universidad de Valladolid, 1998. p. 167-183.

Texto recebido em 06 de março de 2017. Texto aprovado em 13 de abril de 2017. 
